\title{
Overcoming difficult conversations in clinical supervision
}

\author{
This article was published in the following Dove Press journal: \\ Journal of Healthcare Leadership \\ 20 June 2016 \\ Number of times this article has been viewed
}

\author{
Brett Williams' \\ Christine King' \\ Tanya Edlington ${ }^{2}$ \\ 'Department of Community \\ Emergency Health and Paramedic \\ Practice, Monash University, \\ Franskton, VIC, ${ }^{2}$ The Conversation \\ Clinic Pty Ltd, Melbourne, VIC, \\ Australia
}

Correspondence: Brett Williams Department of Community Emergency Health and Paramedic Practice, Faculty of Medicine, Nursing and Health Sciences, Monash University - Peninsula Campus, PO Box 527, McMahons Road, Frankston, VIC 3199, Australia

$\mathrm{Tel}+6$ I 399044283

Fax +6I 399044168

Email brett.williams@monash.edu
Background: Clinical supervisors are responsible for managing many facets of clinical learning and face a range of challenges when the need for "difficult" conversations arises, including the need to manage conflict and relationships.

Methods: Spotlight on Conversations Workshop was developed to improve the capacity of clinical supervisors to engage in difficult conversations. They were designed to challenge the mindset of clinical supervisors about difficult conversations with students, the consequences of avoiding difficult conversations, and to offer activities for practicing difficult conversations. Preworkshop, postworkshop, and 4-month follow-up evaluations assessed improvements in knowledge, intent to improve, and confidence along with workshop satisfaction.

Results: Nine workshops were delivered in a range of locations across Victoria, Australia, involving a total of 117 clinical supervisors. Preworkshop evaluations illustrated that more than half of the participants had avoided up to two difficult conversations in the last month in their workplace. Postworkshop evaluation at 4 months showed very high levels of satisfaction with the workshop's relevancy, content, and training, as well as participants' intention to apply knowledge and skills. Also shown were significant changes in participants' confidence to have difficult conversations not only with students but also with other peers and colleagues. In follow-up in-depth interviews with 20 of the 117 participants, $75 \%$ said they had made definite changes in their practice because of what they learned in the workshop and another $10 \%$ said they would make changes to their practice, but had not had the opportunity yet to do so.

Conclusion: We conclude that the Spotlight on Conversations Workshop can improve the clinical supervisor-student relationship as well as build general difficult conversation capacity for a range of stakeholders in clinical settings.

Keywords: clinical, education, supervision, communication

\section{Introduction}

Clinical supervisors face an array of challenges when the need for "difficult" conversations arises, including the need to manage conflict and relationships. ${ }^{1}$ While many difficult conversations in health care are between doctors and their patients, other difficult conversations include those that take place among health care workers, including students, about performance and climate in the workplace, such as when colleagues make mistakes or display disrespectful behavior. Avoiding difficult conversations in the clinical setting, however, can result in serious negative consequences. For example, the Silence Kills Study that used focus groups, interviews, workplace observations, and survey data from more than 1,700 nurses, physicians, clinical staff, and administrators identified a range of categories of conversations that are especially 
difficult and especially essential for people in health care. ${ }^{2}$ These conversations correlated strongly with medical errors, patient safety, quality of care, staff commitment, employee satisfaction, discretionary effort, and turnover.

VitalSmarts conducted a further study in 2010 "The Silent Treatment" and showed that a culture of silence in organizations leads to communication breakdowns that harm patients. $^{3}$ This study found that more than four out of five nurses have concerns about dangerous shortcuts, incompetence, or disrespect. More than half say shortcuts have led to near misses or harm; more than a third say incompetence has led to near misses or harm; and more than half say disrespect has prevented them from getting others to listen to or respect their professional opinion. In addition, fewer than half of these nurses have spoken to their managers about the person who concerns them the most, and less than a third of these nurses have spoken up and shared their full concerns with the person who concerns them the most.

The human and financial cost of medical errors has been well documented. ${ }^{4-7}$ Much of the research exploring ways to overcome difficult conversations, however, relates to those conversations between a clinician and a patient or patient's family. Given the importance of enabling difficult conversations in the clinical environment in general, there is a need to develop strategies, processes, and tools that can be used by clinicians to have difficult conversations, such as those about mistakes and disrespectful behavior, not only with their students but also with their seniors, peers, and other colleagues.

To address this, funding was provided by Health Workforce Australia to develop a training intervention in the form of a workshop for clinical supervisors and associated toolkit for clinical educators. There were a number of key drivers for developing the workshop and associated toolkit. Health Workforce Australia's Clinical Supervision Support Program has a mandate to develop the clinical supervision capacity and competence across the educational and training sector. To do this, the Clinical Supervision Support Program needs to prepare and educate clinical supervisors and produce a competent clinical supervision workforce. The workshops explicitly linked and aligned with two of the six elements that underpin "best practice" within the clinical learning environment, ${ }^{8}$ including a positive learning environment and effective communication processes. The project was also guided by the National Clinical Supervision Competency Resource produced by Health Workforce Australia, ${ }^{9}$ which offers an overall representation of the clinical supervision competencies required of any health care professional.
The present paper addresses the gap in the literature about nonpatient difficult conversations in the clinical supervisory setting with the following question: Can a training intervention improve clinical supervisors' knowledge, skills, and confidence in conducting difficult conversations? In answering this question, three primary focal points emerge in the paper: First, it documents participating clinical supervisors' self-assessed knowledge, skills, and confidence in conducting difficult conversations. Second, it documents participating clinical supervisors' self-assessed level of confidence in confronting colleagues about mistakes or displays of disrespectful behavior, paying particular attention to differences by colleague type (more junior, peer, or superior). Third, it evaluates the effectiveness of the delivered workshops to improve the knowledge, skills, and confidence of clinical supervisors in conducting difficult conversations.

\section{Methods \\ Design}

This study employed a before and after workshop study repeated measures design and structured in-depth interviews. The Spotlight on Conversations Workshop was developed to improve clinical supervisors' capacity to plan and engage in difficult conversations with students, and to be used as the basis for an educational toolkit for clinical educators. The workshop was also developed to allow clinical supervisors to refresh their knowledge about effective communication and translate this knowledge into clinical education practice. A key focus of the workshop was to challenge the mindset of clinical supervisors about difficult conversations, the consequences of avoiding difficult conversations, and to offer activities that would enable supervisors to practice having difficult conversations. The authors write the word difficult, with reference to difficult conversations, as "difficult", as an assumption that conversations being difficult is a mindset, and as clinical supervisors become more confident and skilled in having these conversations, they appear less difficult, or not difficult at all.

Initially, two 20-minute DVD simulations were developed for use within the workshops. One of these simulations was focused on "student clinical performance" and one was based on "student behavior". The workshop was then designed with a focus on challenging the mindset of clinical supervisors about difficult conversations, the consequences of not having difficult conversations, and to offer activities that would enable supervisors to actually practice difficult conversations. A professional facilitator with wide experience in all 
aspects of communication facilitated our workshop and was supported by the project leader.

A pilot of the workshop was carried out with two Department of Health staff in September 2014 to trial the workshop in terms of relevance, process, and timing. This test run confirmed the necessity and relevance of an advanced workshop on difficult conversations, and some small changes to the process were made as a result of the feedback.

\section{Setting and participants}

A total of 117 clinical supervisors from a range of professions took part in the nine workshops and these were held in a range of locations, both metropolitan and rural, across Victoria, Australia. Inclusion in the workshops included being a clinical supervisor; there were no exclusion criteria. Table 1 illustrates the demographics of participants, including profession, years as a clinical supervisor, training, sex, and age. The predominant profession of participants was nursing (53\%) with speech pathology (16\%), physiotherapy $(9 \%)$, medicine (6\%), and occupational therapy (5\%) being the next four main categories. Other participants were from allied health, social work, nutrition and dietetics, community development, family services, radiation therapy, pharmacy, paramedicine nursing, and podiatry (11\%). In all, 108 of the 117 participants were women. The mean age of participants was 40 ranging from 23 to 72 years, with clinical supervision experience ranging from 1 week to 40 years. Overall, $43 \%$ of participants stated that they had attended previous training in difficult conversations; however, most of this training was a small part of a larger training agenda in a broader topic area (eg, communication skills, clinical supervision).

Participation was through recruitment of volunteers and numbers varied between 11 and 17 per workshop. Participants were recruited via email through the Clinical Training Networks, Victoria, and were undertaken by the Department of Health and Human Services, Victorian State Government. Our experience suggests that a maximum of 12 participants provides the optimal conditions for productive and interactive conversation and practice opportunities. While audiences for these workshops can be uniprofessional or multiprofessional, all of our workshops were multiprofessional.

\section{Educational intervention: workshop delivery}

In September and October 2014, nine workshops in total were delivered across Victoria. Three were delivered in Melbourne Metro locations and six in regional Victoria (Wangaratta, two in Bendigo, Traralgon, Geelong, and Ballarat). Each workshop ran for 3.5 hours and had 12-15 participants in each. Between each of the workshops, facilitators also used a "Plus/Change" process themselves (ie, what was positive and what should be changed) to evaluate the workshop processes (eg, presentation, participant learning, and skills development activities) and the workshop was improved between each delivery. The workshop was made up of ten primary components (Table 2).

Using an overall action-research approach, the workshop process was adapted over time to provide the most effective workshop for inclusion in the toolkit. The delivery of the nine workshops and the development of the toolkit were part of a larger project, "The use of DVD simulations to teach effective communication to clinical supervisors". This project was also designed to add to the body of knowledge surrounding clinical supervision and communication with students.

\section{Evaluation: instrumentation}

An evaluation strategy was developed to assess the success of the workshop process in achieving the workshop aims (ie, capacity building) and to improve on the workshop process; and was both formative and summative. Five evaluation tools formed the basis of the evaluation strategy.

Table I Demographics of participants who took part in workshops

\begin{tabular}{|c|c|c|c|c|c|c|c|}
\hline Supervisor characteristics & $\begin{array}{l}\text { Total } \\
\text { profession } \\
(\mathbf{N}=|| 7)\end{array}$ & $\begin{array}{l}\text { Nursing } \\
(n=62)\end{array}$ & $\begin{array}{l}\text { Speech } \\
\text { pathology } \\
(n=19)\end{array}$ & $\begin{array}{l}\text { Physiotherapy } \\
(n=\mid 0)\end{array}$ & $\begin{array}{l}\text { Medicine } \\
(n=7)\end{array}$ & $\begin{array}{l}\text { Occupational } \\
\text { therapy } \\
(n=6)\end{array}$ & $\begin{array}{l}\text { Others } \\
(n=13)\end{array}$ \\
\hline \multicolumn{8}{|l|}{ Supervisor experience (years) } \\
\hline Range & I week-40 & 6 months -28 & I week-30 & 2 months-16 & $3-20$ & $1.5-40$ & $1-6$ \\
\hline Mean & 6.9 & 6.8 & 4.7 & 7.7 & 11.6 & $10 *$ & 3.4 \\
\hline \multicolumn{8}{|l|}{ Age (years) } \\
\hline Range & $23-72$ & $25-67$ & $24-56$ & $23-42$ & $35-55$ & $24-60$ & $26-72$ \\
\hline Mean & 40 & 42.4 & 36.5 & 33 & 43.6 & 35 & 40.5 \\
\hline Females:males & 108:9 & $59: 3$ & $19: 0$ & $7: 3$ & $6: 1$ & $6: 0$ & $11: 2$ \\
\hline Previous training (\%) & 43 & 45 & 26 & 30 & 71 & 50 & 46 \\
\hline
\end{tabular}

Note: *One participant had a larger number of years of experience compared to other participants (median was 4.5 years). 
Table 2 Workshop components and associated processes

\begin{tabular}{|c|c|}
\hline Component & Process \\
\hline Introduction & $\begin{array}{l}\text { Participants produce a physical scale in response to a series of questions (eg, confidence) and } \\
\text { photographs are taken of participants' placement on the scale. Brief introductions are made while } \\
\text { standing. (I5 minutes) }\end{array}$ \\
\hline Why do conversations matter? & Facilitator introduced a story to participants illustrating the systemic impact when "difficult" \\
\hline Making the case & $\begin{array}{l}\text { conversations were avoided in the health care sector. Participants were asked to add detail to the } \\
\text { story to draw on participant knowledge. Previous research highlighted why conversations matter } \\
\text { from a national and global perspective. (15 minutes) }\end{array}$ \\
\hline $\begin{array}{l}\text { Types of successful conversations: } \\
\text { building on strengths }\end{array}$ & $\begin{array}{l}\text { Participants brainstorm different types of challenging conversations they have in their workplace and } \\
\text { what makes these successful. Parallels are then drawn between these and the types of conversations } \\
\text { and skills that are required for difficult conversations with someone they are supervising to highlight } \\
\text { that they do have skills in difficult conversations that can be drawn from other relationships in their } \\
\text { workplace and lives. (10 minutes) }\end{array}$ \\
\hline Poor feedback and negative language & $\begin{array}{l}\text { Participants watch one of the supplied films of a clinical encounter and follow-up supervisory } \\
\text { conversation. Prior to the film they are provided with two questions to observe during the film } \\
\text { "What is being done well? Does it work?" in relation to body language, questions being asked, } \\
\text { evidence of listening, impact on junior, response, intention, and consequences. After the film, } \\
\text { participants break into groups of three to discuss these questions. ( } 30 \text { minutes) }\end{array}$ \\
\hline Conversation planning and practice & $\begin{array}{l}\text { In small groups of three or "trios", participants take turns in planning and practicing how they } \\
\text { might have a similar conversation in the best way they can. Each participant has a turn at being the } \\
\text { supervisor, the student, and an observer to provide feedback. An action learning process is used to } \\
\text { plan and reflect on the conversations. ( } 50 \text { minutes) }\end{array}$ \\
\hline Good feedback and positive language & $\begin{array}{l}\text { Participants watch the second part of the film showing a good supervisory conversation. Prior } \\
\text { to the film they are reminded of the questions to think about during the film. After the film, } \\
\text { participants break into their groups of three to discuss the questions. ( } 30 \text { minutes) }\end{array}$ \\
\hline Difficult conversation challenges & $\begin{array}{l}\text { Participants think of a conversation scenario of which they are most afraid and the worst things that } \\
\text { could happen if they had the conversation and the worst things that could happen if they avoided } \\
\text { the conversation. From the participant lists, a group list is made and a process is used to compare } \\
\text { and draw conclusions about the group list. (10 minutes) }\end{array}$ \\
\hline Modeling good difficult conversations & $\begin{array}{l}\text { A fishbowl technique is used where a volunteer participant practices having a difficult conversation } \\
\text { that he or she has been avoiding with an actor who takes on the role and persona of the person } \\
\text { he or she has been avoiding having the conversation with. The actor and volunteer swap roles } \\
\text { so that the volunteer can "feel" what it is like to be the person he or she is avoiding having the } \\
\text { conversation with to highlight assumptions he or she has about that person. Other participants } \\
\text { watch good conversations being modeled and provide feedback. ( } 40 \text { minutes) }\end{array}$ \\
\hline Commitment to action & $\begin{array}{l}\text { Participants are asked to reflect on what they have learned in the workshop and asked to think } \\
\text { about what this means in terms of possible actions that they can apply in the workplace. A postcard } \\
\text { activity is then used to have participants commit to one action, enabling them to check if they have } \\
\text { fulfilled this later. ( } 5 \text { minutes) }\end{array}$ \\
\hline
\end{tabular}

\section{Preworkshop registration and baseline evaluation (I week prior)}

This involved a 24-item questionnaire that was completed by all participants, consisting of closed questions, yes/no questions, category selection, Likert scale questions, and open-ended questions. Data collected included demographic data, supervision experience and confidence, and previous education and training. The registration and baseline evaluation data form was from The National Clinical Supervision Skills Initiative of Health Workforce Australia's Clinical Supervision Support Program. Completion of this form is compulsory for all participants attending training events. The Skills Initiative also requires the completion of a survey at the end of the training event and 3 months after the training. These three tools have a primary aim of evaluating the
Skills Initiative and not a participant's personal skills and knowledge. To gain more insight into participants' changes in knowledge, skills, and attitudes, we developed and included additional questions to the end of workshop and 4-month posttraining questionnaire, providing data about knowledge, skills, and attitudes prior to the workshop (time 1), straight after the workshop (time 2), and 4 months after the workshop (time 3). Questions included "How would you describe your knowledge about conducting 'difficult conversations'?", "How would you describe your skills in conducting 'difficult conversations'?", and "How confident are you about having difficult conversations with colleagues?", as well as how confident the participant was in terms of confronting a junior, peer, or senior about a mistake or poor or disrespectful behavior. Other additional questions were "How many 
difficult conversations have you participated in during the last month in your workplace?" and "How many difficult conversations have you avoided in the last month in your workplace?"

\section{Participatory evaluation (beginning and end of workshop)}

Participatory evaluation took place at the beginning and end of the workshop and involved all participants to assess changes in confidence in having difficult conversations. This tool enabled a visual and engaging process for participants, as well as ourselves, with regard to our own training objectives. This involved workshop participants forming a physical scale between 0 and 10 (posted on the wall) at the beginning of the workshop in response to a series of questions. Some of these questions were related to "confidence" and photographs were taken of the physical scale ( 0 being no confidence; 10 being extremely confident). This process was then repeated at the end of the workshop and compared to the photos depicting participant confidence at the beginning of the workshop.

\section{Retrospective pre-post evaluation (end of workshop)}

The retrospective pre-post evaluation was completed at the end of the workshop by all participants and was a 13-item questionnaire including yes/no questions, retrospective before/after Likert scale questions, and open-ended questions. The focus of this evaluation was to assess changes in knowledge, skills and attitudes, and potential factors influencing difficult conversations. Questions also related to the relevancy of the workshop to participants' roles as a clinical supervisor.

\section{Semistructured in-depth phone interviews ( 2 months after workshop)}

The follow-up in-depth phone interviews were designed to evaluate the workshop in more depth than what is possible with surveys/questionnaires. These were undertaken with 20 participants 2 months after workshop delivery ( $20 \%$ sample size). An invitation to participate in the interview was sent out to all previous workshop participants and 20 participants were selected for interview from those who responded. Selection was based on availability within the interview timeframe and ensuring a cross-section of participants who represented those who attended the original nine workshops. Ten nurses (one clinical educator), eight people in allied health (five speech pathologists, two physiotherapists, one community support worker), and two people in medicine were interviewed. Interviews were comprised of five in-depth semistructured interview questions that elicited qualitative data on participant feedback about the workshop, what participants perceived as positive aspects of the workshop and what could be changed to improve the workshop, any changes the participants had made in their practice as a result of the workshop (ie, practice change), thoughts on having different professions involved in the workshop, and topics for future workshops. These five in-depth interview questions took 20-30 minutes for participants to answer.

\section{Follow-up online questionnaire (4 months after workshop)}

The 4-month follow-up online questionnaire was completed by 97 of the 117 participants and involved a 17-item questionnaire including Likert scale and open-ended questions to assess changes in knowledge, skills and attitudes, and potential factors influencing difficult conversations. At the 4-month follow-up, a total of 97 participants completed the questionnaire, a loss of 20 participants from all workshops. The predominant profession of participants was nursing (56\%) with speech pathology (10\%), physiotherapy $(10 \%)$, medicine (4\%), and occupational therapy (6\%) being the next four main categories. Other participants were from allied health, social work, nutrition and dietetics, community development, family services, radiation therapy, pharmacy, paramedicine, and podiatry. A total of 91 of 97 participants were women. The median age of participants was 40 ranging from 23 to 72 years, with clinical supervision experience ranging from 1 week to 40 years. The 4-month follow-up questionnaire was administered over the Christmas holiday period and this was a major reason for the loss of participants. Change of position and change of email address were also reasons.

\section{Evaluation: data analysis}

As our evaluation strategy was both qualitative and quantitative (ie, mixed-method), we used both a deductive and inductive approach. Inductive approaches are generally associated with qualitative research and deductive approaches associated with quantitative research; however, this is not a "rule". Most social science research uses both inductive and deductive approaches (often in a cyclical fashion).

\section{Quantitative data analysis}

The Statistical Package for Social Sciences was used for data storage and tabulation of the quantitative data. Descriptive statistics were used (mean and standard deviation) to describe the participant demographic information. Data were analyzed for changes in knowledge, attitudes, and skills for overall 
participants, as well as different professions and locations using a paired $t$-test. Additional data in terms of experiences with difficult conversations (eg, number of difficult conversations in the past week) were also collected and analyzed.

\section{Qualitative data analysis}

To make sense of the qualitative evaluation data, using an inductive approach enabled moving from specific observations to broader generalizations (ie, a bottom-up approach). With this approach, the research begins with specific observations and measures (ie, specific experiences), then looks for patterns, and then formulates generalizations or theories (ie, propositions about the experiences). This type of approach is more open-ended and exploratory than a deductive approach. To conduct our analysis, we used both simple cut and paste methods in Microsoft Word and manual sticky notes for ranking data or organizing data into themes, rather than a qualitative data analysis package, such as NVivo. This was appropriate and satisfactory for the quantity and type of data that was obtained. The researcher who conducted the analysis was also highly experienced and skilled in qualitative approaches. Where appropriate, qualitative data were converted into quantitative data for presentation, for example, when a certain number of participants had the same response for an open-ended question (eg, seven out of 20 interviewees [35\%] said they could not recommend any improvements to the workshop).

\section{Ethics}

Ethical clearance was obtained prior to the study by the Monash University Human Ethics Committee. Confidentiality was ensured by de-identifying participants on evaluation forms and eliminating references to specific people or organizations in quotes without changing the meaning. Written informed consent was obtained from all participants.

\section{Results}

We present findings from a mixed-method (qualitative and quantitative) evaluation study of nine Spotlight on Conversations Workshops, held over a 2-month period in SeptemberOctober 2014.

\section{Preworkshop registration and baseline evaluation}

The preworkshop evaluations illustrated the extent to which difficult conversations were had or avoided in the clinical setting for clinical supervisors. In all, $47 \%$ of workshop participants had been involved in two difficult conversations and $56 \%$ of workshop participants had avoided up to two difficult conversations that month. Overall, $43 \%$ of participants stated that they had attended previous training in difficult conversations; however, most of this training was a small part of a larger training agenda in a broader topic area (eg, communication skills, clinical supervision).

\section{Retrospective pre-post evaluation}

Regarding the relevancy of the workshop to their roles as a clinical supervisor, the retrospective pre-post evaluation showed very positive findings using a 5-point Likert scale (1, strongly disagree to 5 , strongly agree). For example, the item "The content of the training was relevant to my workplace" produced a mean $=4.96$ (standard deviation $[\mathrm{SD}]$ $=0.20$ ); "The training was important to my role as a clinical supervisor" produced a mean $=4.96(\mathrm{SD}=0.20)$; "I intend to apply the knowledge or skills in my workplace" produced a mean $=4.95$ ( $\mathrm{SD}=0.22)$; and "The facilitator/s were able to relate the subject matter to my local environment" produced a mean $=4.91(\mathrm{SD}=0.29)$.

\section{Pre-post retrospective and follow- up online questionnaires}

Using the pre-post retrospective evaluation and the postworkshop evaluation at 4 months, the impact of the workshops on participants' knowledge, skills, and confidence immediately after the workshop (time 2) and 4 months after the workshop (time 3), compared to before the workshop (time 1), was positive in all questions (Table 3 ).

Other results using a 7-point unipolar Likert rating scale (1, strongly disagree to 7, strongly agree) yielded improved confidence mean scores (Table 4).

Participants were also provided an opportunity to provide narrative feedback on the workshop; a sample of comments is highlighted below:

Really enjoyable and highly recommended to anybody in a supervisory capacity.

The information/content covered was really valuable. I think a full day workshop would be great in order to cover things in more depth.

There are many communication skills that I will use from this training. I have not had training like this before. Found it very helpful. Thank you.

Great to have this kind of practical meaningful training on a topic that affects us all - great facilitation with excellent knowledge!! Would be great as full day training. 
Table 3 Impact of workshops in relation to knowledge, skills, and confidence

\begin{tabular}{|c|c|c|c|c|}
\hline Item & $\begin{array}{l}\text { Mean (SD) } \\
\text { (Time I) }\end{array}$ & $\begin{array}{l}\text { Mean (SD) } \\
\text { (Time 2) }\end{array}$ & $\begin{array}{l}\text { Mean (SD) } \\
\text { (Time 3) }\end{array}$ & $\begin{array}{l}\text { P-value } \\
\text { (Sig) }\end{array}$ \\
\hline $\begin{array}{l}\text { How would you describe your knowledge } \\
\text { about conducting "difficult conversations"? }\end{array}$ & $4.11(1.14)$ & $5.85(1.13)$ & $5.85(1.31)$ & $<0.001$ \\
\hline $\begin{array}{l}\text { How would you describe your skills in } \\
\text { conducting difficult conversations? }\end{array}$ & $3.91(0.70)$ & $5.5 \mathrm{I}(0.70)$ & $4.94(0.85)$ & $<0.001$ \\
\hline $\begin{array}{l}\text { How confident are you about having difficult } \\
\text { conversations with colleagues? }\end{array}$ & $3.8 \mathrm{I}(0.84)$ & $5.38(0.76)$ & $4.98(0.85)$ & $<0.001$ \\
\hline
\end{tabular}

Abbreviations: SD, standard deviation; Sig, significant.

It was a brilliant workshop, and I thoroughly enjoyed the role play opportunity. It is so important.

Thank you for the session. I wish I had have attended prior to a "very difficult conversation" I had with a staff member this morning. The conversation went $\mathrm{OK}-$ but it could have gone better. This will help in future difficult conversations.

\section{Participatory evaluation (beginning and end of workshop)}

Using the participatory physical scale tool to evaluate confidence level, all workshops resulted in an increase in participants' confidence level with regard to having a difficult conversation with a person they are supervising. This was an effective activity to highlight before and after perceptions of participants' confidence.

\section{Semistructured in-depth phone interviews ( 2 months after workshop)}

In the follow-up in-depth interviews, $75 \%$ of participants said they had made definite changes in their practice because of what they learnt in the workshop. Overall, $10 \%$ of participants said they felt they would make changes to their practice, but had not had the opportunity yet in their supervision. The remaining $15 \%$ of participants stated that they could not identify any specific practice change but that they had been supervising for a long time and the workshop gave them an opportunity to refresh their skills. The two main practice changes stated were changes in the way participants planned their difficult conversations and actually having difficult conversations rather than avoiding them. Other changes included having more conscious goals and outcomes, thinking more strategically about difficult conversations, having improved communication, more confidence, entering into conversations with evidence, and being more encouraging, compassionate, and positive.

Seven out of 20 interviewees said they could not recommend any improvements to the workshop (35\%). Almost all other interviewees suggested improvements that were a positive reflection on the workshop. These included increasing the time of the workshop to include more time to practice difficult conversations, expanding the workshop to include more staff both vertically and horizontally (eg, managers, doctors, rural, and remote staff), and dividing small groups by years of experience when conducting small group activities. One

Table 4 Confidence mean scores of participants

\begin{tabular}{|c|c|c|c|c|}
\hline Item & $\begin{array}{l}\text { Mean (SD) } \\
\text { (Time I) }\end{array}$ & $\begin{array}{l}\text { Mean (SD) } \\
\text { (Time 2) }\end{array}$ & $\begin{array}{l}\text { Mean (SD) } \\
\text { (Time 3) }\end{array}$ & $\begin{array}{l}\text { P-value } \\
\text { (Sig) }\end{array}$ \\
\hline \multicolumn{5}{|l|}{ I am confident to confront someone more } \\
\hline junior about a mistake that they have made & $4.97(1.23)$ & $6.09(.80)$ & $6.10(.82)$ & $<0.001$ \\
\hline \multicolumn{5}{|l|}{ I am confident to confront a peer about a } \\
\hline mistake that he or she have made & $4.30(1.34)$ & $5.50(.91)$ & $4.86(.62)$ & $<0.001$ \\
\hline \multicolumn{5}{|l|}{ I am confident to confront a superior about } \\
\hline a mistake that they have made & $3.56(1.44)$ & $4.88(1.23)$ & $5.01(1.08)$ & $<0.001$ \\
\hline \multicolumn{5}{|l|}{ I am confident to confront someone more } \\
\hline junior about poor or disrespectful behavior & $4.80(1.30)$ & $5.97(0.79)$ & $6.05(0.75)$ & $<0.001$ \\
\hline \multicolumn{5}{|l|}{ I am confident to confront a peer about } \\
\hline poor or disrespectful behavior & $4.22(1.25)$ & $5.47(0.93)$ & $5.53(0.77)$ & $<0.001$ \\
\hline \multicolumn{5}{|l|}{ I am confident to confront a superior } \\
\hline about poor or disrespectful behavior & $3.38(1.21)$ & $4.76(0.98)$ & $4.95(0.65)$ & $<0.001$ \\
\hline
\end{tabular}

Abbreviations: SD, standard deviation; Sig, significant. 
interviewee suggested that the introductory activity was too long. In terms of what was good, $\sim 50 \%$ of participants stated that the fishbowl activity (where they could "see" expert modeling of a difficult conversation) was the best part of the workshop. Other specific activities that were mentioned by many of the interviewees were 1) the role play (ie, real play) where participants could practice a difficult conversation and 2) being presented with information and statistics that illustrated the importance of having difficult conversations (including the "what if I do? and what if I don't?" activity). Also, in response to what was good about the workshop, 50\% of participants mentioned the overall interactive processes and group work. Two participants stated that the workshop made them feel relieved knowing that they were not the only one experiencing difficulties with difficult conversations.

When asked "What did you think about different professions being involved in the workshop?" and "Is there anything that is specific to your profession that might need to be highlighted in terms of further workshops and toolkits?", 19 out of 20 said that having different professions was beneficial. Reasons included:

Not getting bogged down in the content of a profession.

Seeing that other professions are having the same issues and you are not alone.

Aligning to allied health strategies.

Aligning to similarity and highlighting that we are all patient focused.

More openness to talk because more diversity means you are less likely to be in workshop with everyone you work with.

Team focused where we are all working together, a lot of crossover.

One person said that it would be good to have just done the workshop with nurses stating that different professions have different expectations. There was a general consensus that the principles required for the workshop are generic across the board:

It is the ability of the person who is reading that stuff how to adapt it to that area. A difficult conversation is a difficult conversation.

Speech pathology was highlighted as requiring something extra in terms of future workshops, stating that this profession is dealing with communication as the process and content of practice. Also highlighted was the need to include something extra to address difficulties that arise with patients where English is a second language and where English is a second language for staff. Different professions having different legal requirements and different assessments (eg, some professions have no second chances and some do) were also suggested in terms of additional aspects to future workshops/toolkits.

\section{Reflections on facilitating the workshop}

This workshop was designed to help clinical supervisors come to terms with their fear and the consequences of letting that fear drive their behavior when it comes to engaging in conversations with people they supervise (and anyone else for that matter!). Most people have been taught frameworks for feedback and having the so-called difficult conversations. The obstacle that stops the conversations happening is not a lack of method; it is often a fear-driven mindset. Adding more frameworks to the toolkit does not generally lead to people engaging in the conversations they need to have. What if the consequences of avoidance are more serious than the consequences of engagement? Understanding this is the heart of the shift in mindset which can lead to attitude and then behavior change.

As our facilitator progressed through the series of workshops, she became acutely aware that often she was engaging in what might be considered to be a difficult conversation - whether this was with an individual or with the group at large. That is, the facilitator became a role model to participants using processes and language that modeled good communication and feedback, were inquiry-based, inclusive, and positive, and allowed for diversity and feedback from participants. Being confident to model these conversations is essential for anyone facilitating these workshops.

Another intention that was built into the design of the workshop is the idea that participants will draw their own conclusions about the necessity and benefits of engaging in any conversation that is necessary if the arguments are made. This is designed with a facilitation approach (rather than a training approach) in mind. That is, a key strategy was to purposefully integrate critical reflection to enable participants to discover for themselves their own capacity and skills for having difficult conversations.

References to relevant peer reviewed literature, theory, and cases about difficult conversations and missed opportunities in the health sector were incorporated to make the case for having difficult conversations. The project's academic lead was also present at each workshop and provided input relating to clinical supervision where relevant. While this combination of skills and knowledge is ideal for facilitating the workshops, it is recognized that this will not always be 
feasible. Successful workshops should focus on facilitation skills rather than purely clinical skills.

When run with a multiprofessional group of participants, the workshop had additional benefits, including enabling shared understandings of care, being patient-focused, feeling less isolated, and being able to separate clinical supervision process from profession-based difficulties, norms, and beliefs.

We found other topics which assisted our preparation to facilitate the workshops included patient safety; reducing medical errors; medical malpractice; difficult conversations in clinical supervision; health care teams; interprofessional collaboration; overcoming difficult conversations; channels of face to face communication; emotional intelligence; building rapport; active listening; and providing feedback.

Our facilitator stocked her facilitator's toolkit with curiosity and a desire to question rather than answer. She made it clear that there is no "perfect" conversation and that conversations are necessary to functioning relationships, whether personal or professional. At the end of every workshop, she reflected on what went well and what she needed to change or be aware of. Our facilitator also sought feedback from colleagues who observed the workshops. This approach was essential to support her work in the facilitation of a challenging workshop.

\section{Discussion}

This article has reported on the implementation and evaluation of a series of interprofessional workshops for building the capacity of clinical supervisors to engage in difficult conversations with students. Feedback during our workshops and from our evaluations showed that workshop participants saw that what they had learned had a much wider application: building their confidence to have difficult conversations with not only students, but also their peers, seniors, and other colleagues.

Donaldson and Carter ${ }^{10}$ suggest that although the importance of role modeling is acknowledged within the literature, there is little written about the value of providing role modeling within the clinical learning environment to facilitate learning for student nurses. Their research found that students rated the access to good role models highly, having a large influence on student's confidence and competence. As such, Donaldson and Carter made recommendations to include role modeling in mentor preparation courses. Our workshops took note of these findings and were specifically designed to integrate appropriate attitude and modeling behavior, which was the most appreciated component of the workshops as reported by participants.

Our postworkshop in-depth interviews showed that $75 \%$ of participants had made specific practice changes as a result of our workshop and a further $10 \%$ of participants said they had not had the chance to supervise any students since the workshop, but outlined specific strategies they would now use when they next had the opportunity to supervise. We suspect these high levels of practice change were predominantly the result of the purposeful integration of critical reflection in our workshops, particularly through action learning, although additional research would be needed to confirm this. Although reflective practice has a long history in the education literature, Senediak ${ }^{11}$ points out that the role of reflective practice has only recently extended to the counseling and supervision arenas.

Reflection in supervision allows the supervisee to 'step back' and 'consider alternatives' so that change can take place in that situation and be generalised to other situations as well. ${ }^{11}$

One limitation of our workshops and evaluations is that the workshops took place in regional centers and not in very remote locations. Feedback from our follow-up in-depth evaluation suggested that more workshops were needed in more remote locations where clinical supervisors have fewer resources and less training opportunities. From this, we can only assume that some of the statistics we found in our evaluation process may not be completely representative of rural and remote areas. We can deduce from this, however, that people working in remote areas may have less opportunity for skills development, which may lead to more conversations being avoided. This consolidates our findings and suggests an even greater need for workshops in remote areas. Another limitation is that all data about participating clinical supervisors' knowledge, skills, and confidence in conducting difficult conversations, as well as any changes made in practice or plans to do so, are self-reported. More rigorous assessment tools with larger samples of clinical supervisors would be needed to verify these data. In addition, participation in the workshops was voluntary and based on recruitment efforts, which might have introduced a self-selection bias of clinicians who were already keen to address this issue and therefore more likely to evaluate it positively and implement their learning in practice. In spite of these limitations, the study contributes to the literature by focusing on nonpatient difficult conversations clinical supervisors encounter with the full range of colleagues (more junior, peer, and superior) and the 
impact a training intervention can have on their knowledge, skills, and confidence to engage in them.

\section{Conclusion}

The Spotlight on Conversations Workshops challenge and change the mindset of clinical supervisors on what is a difficult conversation and the consequences of avoiding conversations, as well as provide supervisors with the skills to plan and engage in difficult conversations with students. The application of these skills also extends to their own peers, colleagues, and supervisors. Key strategies to the success of the workshop included critical reflection, participants discovering their own capacities and skills through inquirybased processes, role modeling of good communication by the facilitator, being inclusive and positive, allowing for diversity and feedback, and running the workshops with multiprofessional groups. Evaluations showed that participants wanted more time to practice difficult conversations during the workshop and participants also suggested that the workshop needed to be run with more staff, at all levels, and in more remote places. Although the workshop appears replicable and may have broad generalizability, it was evident from evaluations and discussions with the Department of Health, Victoria, that more training would be required to enhance the capacity of departmental staff to run the Spotlight on Conversations Workshop themselves. More research on the impact of improved planning and actually engaging in difficult conversations on the reduction of medical errors are required in the Australian context. Future directions are currently being discussed with project partners.

\section{Acknowledgments}

This project was possible due to funding made available by Health Workforce Australia. We would also like to thank and acknowledge the following staff from the Department of Health and Human Services, Victorian State Government: Anita Hill, Fiona O'Leary, Matt Jenkins, and Amanda Reeves who all provided support and advice throughout the project. Finally, we would like to thank all the supervisors who participated in the workshops.

\section{Disclosure}

The authors report no conflicts of interest in this work.

\section{References}

1. Browning DM, Meyer EC, Truog R, Solomon MZ. Difficult conversations in health care: cultivating relational learning to address the hidden curriculum. Acad Med. 2007;82:905-913.

2. Maxfield D, Grenny J, McMillan R, Patterson K, Switzler A. Silence Kills: The Seven Crucial Conversations for Healthcare. Provo, UT: VitalSmarts; 2005.

3. Maxfield D, Grenny J, Lavandero R, Groah L. The Silent Treatment: Why Safety Tools and Checklists Aren't Enough to Save Lives. Provo, UT: VitalSmarts; 2010.

4. Waring JJ. Beyond blame: cultural barriers to medical incident reporting. Soc Sci Med. 2005;60(9):1927-1935.

5. Kalra J, Kalra N, Baniak N. Medical error, disclosure and patient safety: A global view of quality care. Clin Biochem. 2013;46:1161-1169.

6. Richardson J, McKie J. Reducing the Incidence of Adverse Events in Australian Hospitals: An Expert Panel Evaluation of Some Proposals. Victoria: Monash University; 2007.

7. Wilson RM, Runciman WB, Gibberd RW, Harrison BT, Newby L, Hamilton JD. The quality in Australian health care study. Med J Aust. 1995;163(9):458-471.

8. The Best Practice Clinical Learning Environment Framework: Quality Clinical Education in Victoria. Melbourne, Victoria: Department of Health, Victoria; 2013.

9. National Clinical Supervision Competency Resource - Validation Edition. Adelaide, South Australia: Health Workforce Australia; May 2013. HWA13CTR009.

10. Donaldson JH, Carter D. The value of role modelling: Perceptions of undergraduate and diploma nursing (adult) students. Nurse Educ Pract. 2005;5(6):353-359.

11. Senediak C. A reflective practice model of clinical supervision. Paper presented at: Advances in Clinical Supervision Conference; 2013; Sydney, Australia.
Journal of Healthcare Leadership

\section{Publish your work in this journal}

The Journal of Healthcare Leadership is an international, peer-reviewed, open access journal focusing on leadership for the health profession. The journal is committed to the rapid publication of research focusing on but not limited to: Healthcare policy and law; Theoretical and practical aspects healthcare delivery; Interactions between healthcare and society and evidence-based practices;

\section{Dovepress}

Interdisciplinary decision-making; Philosophical and ethical issues; Hazard management; Research and opinion for health leadership; Leadership assessment. The manuscript management system is completely online and includes a very quick and fair peer-review system. Visit http://www.dovepress.com/ testimonials.php to read real quotes from published authors. 